\title{
Sildenafil augments the effect of inhaled nitric oxide for postoperative pulmonary hypertensive crises
}

\author{
Andrew M. Atz, MD, ${ }^{a}$ Amy K. Lefler, PharmD, ${ }^{\mathrm{b}}$ David L. Fairbrother, MD, ${ }^{\mathrm{a}}$ Walter E. Uber, PharmD, ${ }^{\mathrm{b}}$ and \\ Scott M. Bradley, MD, ${ }^{\mathrm{C}}$ Charleston, SC
}

$\mathrm{P}$ ulmonary hypertension remains a major complication after surgical correction of congenital heart disease. Inhaled nitric oxide (NO) has been shown to reduce, but not eliminate, potentially life-threatening episodic pulmonary hypertensive crises. ${ }^{1} \mathrm{NO}$ increases intracellular cyclic guanosine monophosphate (cGMP), resulting in smooth muscle vasodilation. Phosphodiesterase type 5 (PDE5) is responsible for cGMP breakdown in lung tissue. We hypothesized that sildenafil (Viagra; Pfizer Laboratories, New York, NY), a selective and potent inhibitor of PDE5, may augment pulmonary vasodilation with NO and reduce the risk of pulmonary hypertensive crises in an at-risk postoperative patient.

\section{Clinical Summary}

A 9-month-old boy with congenital mitral stenosis underwent supra-annular valve replacement with a $16-\mathrm{mm}$ Carbomedics prosthesis (Sulzer Carbomedics, Austin, Tex). Postoperative support included dopamine at $7 \mu \mathrm{g} \cdot \mathrm{kg}^{-1} \cdot \mathrm{min}^{-1}$, milrinone at 0.75 $\mu \mathrm{g} \cdot \mathrm{kg}^{-1} \cdot \min ^{-1}$, muscle relaxation with vecuronium at 0.1 $\mathrm{mg} \cdot \mathrm{kg}^{-1} \cdot \mathrm{h}^{-1}$, sedation with fentanyl at $20 \mu \mathrm{g} \cdot \mathrm{kg}^{-1} \cdot \mathrm{h}^{-1}$, and controlled hyperventilation to a $\mathrm{pH}$ of greater than 7.5 and $\mathrm{Po}_{2}$ of greater than $200 \mathrm{~mm} \mathrm{Hg}$. Left atrial pressure was $17 \mathrm{~mm} \mathrm{Hg}$, pulmonary artery pressure was 74/44 $\mathrm{mm} \mathrm{Hg}$ (mean, $54 \mathrm{~mm} \mathrm{Hg}$ ), and systemic blood pressure was $91 / 38 \mathrm{~mm} \mathrm{Hg}$ (mean, $57 \mathrm{~mm}$ $\mathrm{Hg}$ ). Inhaled NO given 2 hours after the operation produced a selective $31 \%$ decrease in mean pulmonary artery pressure and was continued at $20 \mathrm{ppm}$. Despite these medical maneuvers, the infant had recurrent pulmonary hypertensive crises (abrupt increases in pulmonary artery pressure accompanied by decreases in systemic pressure and oxygen saturation) during endotracheal suctioning, as well as other noxious stimuli. When this clinical status persisted by postoperative day (POD) 4 , an initial dose of sildenafil $(0.3 \mathrm{mg} / \mathrm{kg})$ administered through a nasogastric tube showed an augmented decrease in pulmonary artery pressures with no change

From the Division of Pediatric Cardiology, ${ }^{\text {a }}$ College of Pharmacy, ${ }^{\mathrm{b}}$ and Division of Cardiothoracic Surgery, ${ }^{\mathrm{c}}$ Medical University of South Carolina, Charleston, SC

Received for publication Feb 26, 2002; accepted for publication March 29, 2002.

Address for reprints: Andrew M. Atz, MD, Director, Pediatric Cardiac Intensive Care, Children's Heart Program of South Carolina, Medical University of South Carolina, 165 Ashley Ave, PO Box 250915, Charleston, SC 29425 (E-mail: atzam @ musc.edu).

J Thorac Cardiovasc Surg 2002;124:628-9

Copyright $(9) 2002$ by The American Association for Thoracic Surgery

$0022-5223 / 2002 \$ 35.00+0 \quad \mathbf{1 2 / 5 4 / 1 2 5 2 6 5}$

doi: $10.1067 / \mathrm{mtc} .2002 .125265$ in heart rate, oxygen saturation, or systemic blood pressure (Figure 1). Sildenafil ( $0.3 \mathrm{mg} / \mathrm{kg}$ per dose) was then given every 4 hours. No further pulmonary hypertensive events were provoked during endotracheal suctioning or other stimuli. Vecuronium was stopped on POD 7, and NO was weaned slowly: $20 \mathrm{ppm} \times 4$ days, 15 ppm $\times 3$ days, $10 \mathrm{ppm} \times 1$ day, $5 \mathrm{ppm} \times 5$ days, $3 \mathrm{ppm} \times 1$ day, and weaned off over 4 hours on POD 15 . Mean pulmonary artery pressure was directly measured throughout and remained $60 \%$ to $70 \%$ of mean systemic blood pressure during this entire course. He was extubated on POD 21, and sildenafil was discontinued on POD 22. No rebound phenomenon was seen over the next 36 hours, and the pulmonary arterial catheter was removed on POD 23 with discharge from the intensive care unit the following day.

\section{Discussion}

Previous reports describe the use of single doses of sildenafil to augment and prolong the pulmonary vasodilator effect of NO in a small cohort of adults during cardiac catheterization ${ }^{2}$ and to allow successful discontinuation of inhaled NO in children after cardiac surgery in whom NO withdrawal had previously failed. ${ }^{3}$ Prolonged therapy with sildenafil has been reported in one child with primary pulmonary hypertension. After treatment failure with NO and parenteral prostacyclin, sildenafil $(2 \mathrm{mg} / \mathrm{kg}$ every 4 hours) resulted in decreased tricuspid regurgitation after 4 weeks of therapy. 4

The terminal half-life of sildenafil is approximately 4 hours, and its elimination is primarily through a hepatic route. ${ }^{5} \mathrm{We}$ treated with sildenafil every 4 hours by using a 0.3 to $0.35 \mathrm{mg} / \mathrm{kg}$ dose, as described previously. ${ }^{3}$ With direct continuous monitoring of pulmonary artery and systemic blood pressure, we noted a sustained therapeutic effect on pulmonary artery pressures and observed no systemic hypotension with prolonged dosing at this interval.

When added to NO, we found low-dose sildenafil to be a safe and effective therapy for pulmonary hypertension, preventing further pulmonary hypertensive crises associated with noxious stimuli. Sildenafil exhibited additive effects with NO on pulmonary tone that were sustained during prolonged use and facilitated weaning from NO. Sildenafil and other selective PDE5 inhibitors with improved selectivity, shorter onset of action, and longer half-life merit further carefully designed exploration for the treatment of pulmonary hypertension. Until prospective studies investigate the pharmacokinetics, as well as other potential limitations and unknown side effects, of this drug, extreme caution must be taken in patients who may have high circulating levels of cGMP, those receiving oral or intravenous nitrates, and those with hepatic dysfunction. 


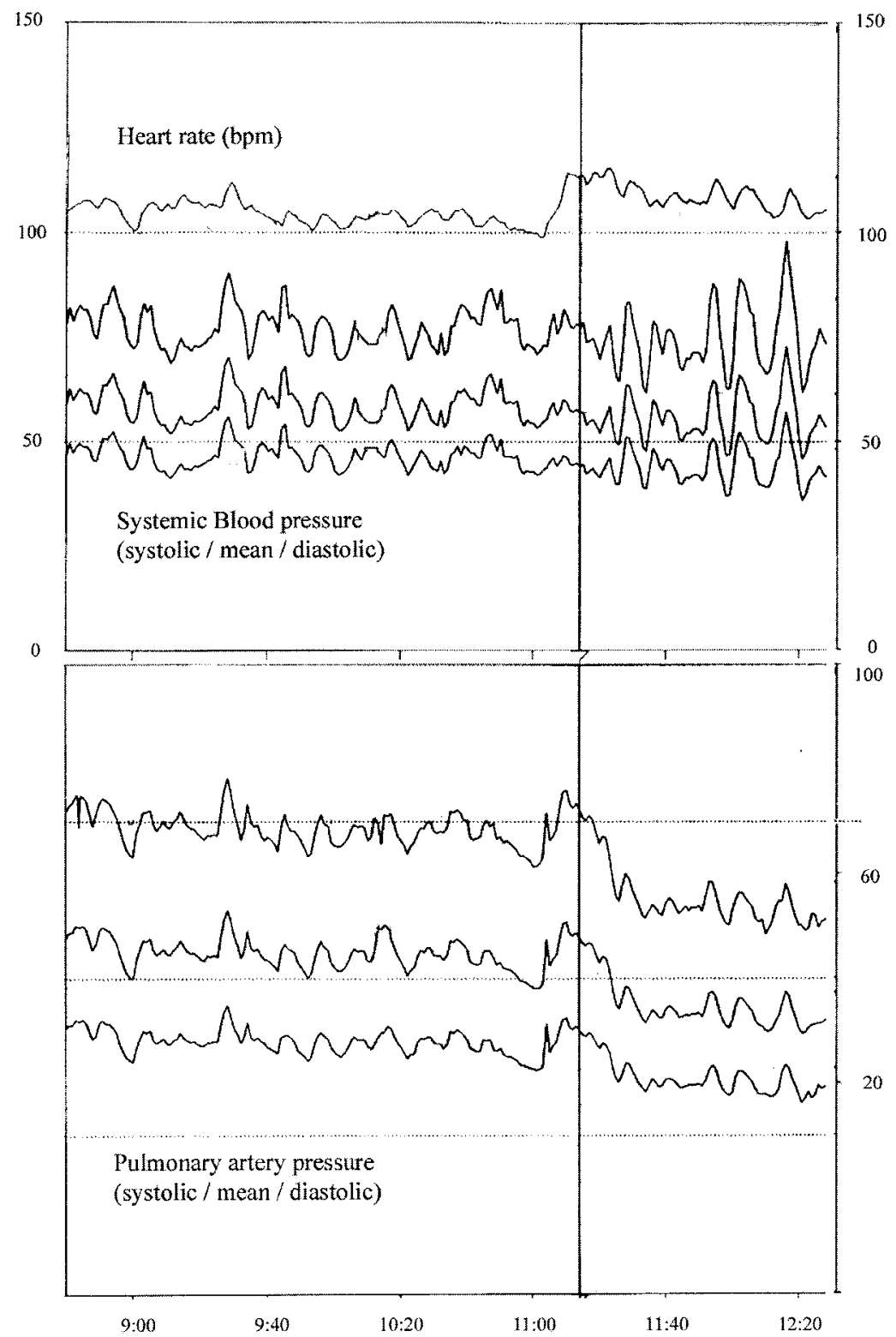

Figure 1. Continuous traces of heart rate, blood pressure (systolic, mean, and diastolic), and pulmonary artery pressure (systolic, mean, and diastolic) recorded every minute. Despite treatment with NO at 20 ppm for 4 days, the patient had persistently elevated pulmonary artery pressure. A $0.3 \mathrm{mg} / \mathrm{kg}$ dose of sildenafil given at the cursor caused additional selective pulmonary vasodilation.

\section{References}

1. Miller OI, Tang SF, Keech A, Pigott NB, Beller E, Celermajer DS. Inhaled nitric oxide and prevention of pulmonary hypertension after congenital heart surgery: a randomized double-blind study. Lancet. 2000;356:1464-9.

2. Lepore JJ, Pereira N, Maroo A, Ginns L, Bigatello LM, Dec GW, et al. Sildenafil is a pulmonary vasodilator which augments and prolongs vasodilitation by inhaled nitric oxide in patients with pulmonary hypertension [abstract]. Circulation. 1999:100(Suppl):I-240.

3. Atz AM, Wessel DL. Sildenafil ameliorates effects of inhaled nitric oxide withdrawal. Anesthesiology. 1999;91:307-10.

4. Abrams D, Schulze-Neick I, Magee AG. Sildenafil as a selective pulmonary vasodilator in childhood primary pulmonary hypertension. Heart. 2000;84:E4.

5. Glossmann H, Petrischor G, Bartsch G. Molecular mechanisms of the effects of sildenafil (VIAGRA). Exp Gerontol. 1999;34:305-18. 